\title{
Impacts of Parameter Uncertainty and Seasonal Variation on a Regional Model
}

\author{
Benjamin J. Sherman and Mark J. TenBroek
}

The most recent release of the City of Detroit regional sewerage collection system SWMM model includes refinements and/or improved characterization of various model parameters such as directly connected impervious area (DCIA), rainfall dependent inflow and infiltration (RDI/I) and dry weather flow (DWF). After these improvements to the model were implemented, the Michigan Department of Environmental Quality (MDEQ) requested that the uncertainty in model parameters and the impacts of this uncertainty on the model results be evaluated. In addition to model parameter uncertainty, the seasonally varying parameters were evaluated to assess the impacts of temporal distribution. A simplified approach to evaluating the temporal distribution in seasonally varying parameters was used by comparing model results of annually averaged conditions and seasonally varying value conditions. The parameter uncertainty impacts analyses were based on a new assessment approach. The results suggest using this approach in lieu of sensitivity analysis. This approach and subsequent results are discussed in this chapter.

\subsection{Introduction}

The Detroit Water and Sewerage Department (DWSD) developed the Greater Detroit Regional Sewer System (GDRSS) model using a modified EPA SWMM to evaluate reduction of combined sewer overflows. The GDRSS collects flows

\footnotetext{
Sherman, B.J. and M.J. TenBroek. 1999. "Impacts of Parameter Uncertainty and Seasonal Variation on a Regional Model." Journal of Water Management Modeling R204-12. doi: 10.14796/JWMM.R204-12. (c) CHI 1999 www.chijournal.org ISSN: 2292-6062 (Formerly in New Applications in Modeling Urban Water Systems. ISBN: 0-9697422-9-0)
} 
from the City of Detroit and all or part of 76 surrounding communities covering nearly 2,300 square kilometers and serving nearly three million people. The hydrologic model consists of 337 distinct subbasin drainage areas, and the hydraulic model consists of over 1,400 explicitly modeled conduits. Throughout the project development, uncertainty in model parameters has been a concern. At the request of the Michigan Department of Environmental Quality, the variability in model results due to parameter uncertainty was evaluated.

To address this issue, an approach was developed to investigate parameter impacts on continuous and event model results. The parameters that were investigated include: Manning's $n$, storage, river elevation boundary conditions, dry weather flow, directly connected impervious area, depression storage, evaporation, Horton's infiltration and regeneration, routing channels, RDI/I shape, and RDI/I volume. A second important component of model parameters is that of temporal, or seasonal, variation of some of the aforementioned parameters. This seasonal variation was also evaluated to determine the impacts on model results relative to annually averaged values of dry weather flow, evaporation and RDI/I volume parameters. Impacts of seasonal variation were evaluated for the continuous model using both an annual and a seasonal extreme period (representing a wetter period of the year in Detroit, March through May).

The analysis of parameter impacts was performed in a similar manner to typical model sensitivity analysis. However, unlike typical sensitivity analysis, the parameter values were varied by percent of range instead of by percent of value. The results provide insight into both parameter uncertainty and model sensitivity to the given parameter. However, there can be no distinction between the degree of impact due to uncertainty and sensitivity. The uncertainty in a model parameter will produce impacts and the extent of these impacts will of course depend on the range in which the parameter varies and the model's sensitivity to this same parameter. Works such as those by James and Kuch (1998) effectively describe the sensitivity analysis process for the reader to make a detailed comparison to the approach described herein. The objective of this chapter is to provide a basis for improving the understanding of model parameter uncertainty with respect to specific parameter impacts on model results. For the seasonal variation, however, differences in results represent strictly the model's sensitivity either including seasonal variation or not (not, being the annually averaged parameter value).

The 47 model simulations' (20 continuous, 25 event and two baseline simulations) results were evaluated to quantify discharge to the Detroit collection system from suburban districts as well as overflow occurring before entry into the Detroit system. Within Detroit, the flow to the wastewater treatment plant (WWTP) and overflow were evaluated. All results were compared to the baseline model conditions with a detailed accounting of continuity error impacts. Conclusions are presented in terms of the relative impacts of these parameters with respect to parameter uncertainty and the model sensitivity. 


\subsection{Background}

Typically, sensitivity analysis is performed early in a model's calibration to identify aspects of the model that require additional data collection. Furthermore, it can identify model parameters that have little impact on the output regardless of the parameter value chosen. For this project, a parameter impacts analysis was performed on the calibrated/validated model to provide model uncertainty information from the parameter-input perspective. The parameter impact analysis can be considered in terms of degree and direction of impact just as during a sensitivity analysis. In summary, sensitivity analysis is similar to the work presented in this chapter; however, the approach discussed in this chapter provides a means to assess the model sensitivity to uncertainty in the parameters.

The approach used is a parameter-by-parameter perturbation leading to critical parameter identification, model sensitivity, and insight to impacts of parameter uncertainty on model results. The validity of the results depends greatly on reasonable ranges of the model parameter values. Selecting reasonable ranges over which parameters are allowed to vary ensures that the deterministic nature of the model with respect to the parameter/process in question is maintained. Just as prior to calibrating a model, reasonable ranges for parameters should be identified. If parameter values are used outside of a reasonable range, the deterministic nature of the model is compromised and the calibration becomes a fitting process with the parameters acting merely as empirical constants. Similarly, a parameter impacts analysis should strive for deterministic conditions.

It is important to note that parameters with high uncertainty can yield low model impacts and sensitive parameters with low uncertainty can yield high model impacts. The advantage over a typical sensitivity analysis is that by perturbing the parameter by percent of range may allow the impacts to reflect the level of confidence in the parameter in conjunction with model sensitivity. For example, a parameter for which the model is highly sensitive, but for which the modeler has a high degree of certainty, will yield significantly lower impacts than a typical sensitivity analysis. This assumes that the perturbation of the parameter by percent of range is lower than by percent of value as would be expected relative to most sensitivity analysis (say $+/-20 \%$ of value versus $+/-20 \%$ of range should in most cases yield a larger perturbation).

One should note that this approach provides linear information only. More advanced sensitivity analysis techniques, such as Monte Carlo or Fourier analyses, could be employed to evaluate nonlinear parameter impacts. However, the parameter perturbation by percentage of range versus percentage of value remains an important consideration regardless of sensitivity analysis technique employed. 


\subsection{Approach}

\subsubsection{Parameter Selection}

Parameters selected for these analyses were based on the GDRSS user experience with the model. This experience includes model development, sensitivity analyses, calibration and validation of the continuous and event models. Furthermore, parameters were chosen for which new methodology was developed or for which substantially increased detail was added throughout the project. During the GDRSS project, new methodology was developed regarding parameter spatial distribution such as, RDI/I C factors that vary as a function of sewer construction age. Furthermore, substantially increased detail was added such as, the modeling of seasonal variation in DWF. Table 12.1 lists the parameters considered for the evaluations.

\subsubsection{Range Selection and Application to Model}

After selecting the parameters for which impacts on model results were evaluated, the ranges of these parameters were established. The approach used to select the ranges varied by parameter. The selection of ranges was based on available data, literature, physical limitations such as $0<\mathrm{DCIA}<100$, or code limitations such as array size. Array size was a limitation for the RDI/I shape parameter evaluation. Ideally, this simulation should be performed again with the upper limit of the array extended. In all cases, experience and judgment were used while evaluating the available data. In some cases, enough data were available to statistically determine confidence intervals for use as ranges. By establishing reasonable ranges, the variation observed in the model results indicates how the uncertainty in a parameter impacts the model output. For example, if a parameter is at best known to be within a three order of magnitude range, e.g. the Horton's regeneration parameter, and the model results indicate minimal impact, the uncertainty in the parameter translates to minimal concern regarding the uncertainty in the parameter. This same result also indicates low model sensitivity to the parameter.

Ranges were established for all parameters considered with the exception of routing channels, storage, and RDI/I shape. In the cases of routing channels and RDI/I shape parameters, insufficient data were available to provide estimates for reasonable ranges. Also, storage was added in relatively small quantities to minimize model instabilities in certain locations in the modeled system. The impacts on the model output due to pseudo-storage as a numerical control were also evaluated. For those parameters with established ranges, each parameter value in the model's input files was perturbed by plus and minus $50 \%$ of range. Applying $50 \%$ of range to each parameter in the model can produce parameter 
Table 12.1 Parameter selection.

\begin{tabular}{|c|c|c|}
\hline Parameter & Input Files Modified & Card and Variable Name \\
\hline \multicolumn{3}{|l|}{ Baseline } \\
\hline GDRSS Model Condtions & & -- \\
\hline \multicolumn{3}{|l|}{ Seasonal Variation Impacts } \\
\hline Non Seasonal & RUNOFF, EXTRAN, TRANSPORT & see below \\
\hline Dry Weather Flow & EXTRAN, TRANSPORT & B9 or B4 group \\
\hline RDII Volume & RUNOFF & $\begin{array}{l}\text { F4 DSTORE, F4 STORAGE, } \\
\text { F4 DREC and H5 RDIIR }\end{array}$ \\
\hline Evaporation & RUNOFF & F1 group \\
\hline \multicolumn{3}{|l|}{ Parameter Impacts } \\
\hline \multicolumn{3}{|l|}{ Baseline } \\
\hline Mannings " $n$ " & EXTRAN & C1 ROUGH \\
\hline Storage & EXTRAN & E1 ASTORE and E2 QCURVE \\
\hline River Elevation & EXTRAN & $\mathrm{J} 2 \mathrm{Al}$ \\
\hline Dry Weather Flow & EXTRAN, TRANSPORT & B9 or B4 group \\
\hline DCIA & RUNOFF & HI WW(3) \\
\hline Depression Storage & RUNOFF & $\begin{array}{l}\text { H1 WSTORE1 and H1 } \\
\text { WSTORE2 }\end{array}$ \\
\hline Evaporation & RUNOFF & F1 group \\
\hline Horton's Infiltration & RUNOFF & $\begin{array}{l}\text { H1 WLMAX, H1 WLMIN, H1 } \\
\text { DECAY and B4 REGEN }\end{array}$ \\
\hline Routing Channels & RUNOFF & $\begin{array}{l}\text { two G1 GLEN and one G2 } \\
\text { SPILL }\end{array}$ \\
\hline RDII Shape & RUNOFF & $\begin{array}{l}\text { two F4 RDIIT, two F4 RDIIK } \\
\text { and two H5 RDIIR }\end{array}$ \\
\hline RDII Volume & RUNOFF & $\begin{array}{l}\text { F4 DSTORE, F4 STORAGE, } \\
\text { F4 DREC and H5 RDIIR }\end{array}$ \\
\hline
\end{tabular}

values outside of the pre-specified reasonable range if the baseline value does not coincide with the midpoint of the respective parameter's range. Although it is desired to maintain the deterministic nature of the model throughout this analysis, this simplification was made to facilitate production of the results. It is assumed that the average of all values for a given parameter would remain within the reasonable range and that the overall results do not represent a significantly compromised deterministic model. The following paragraphs summarize the treatment of the individual parameters with respect to range selection and application. 


\section{Manning's $n$}

The EXTRAN Manning's $n$ parameter for pipe roughness has a range of 0.002 (Potter et al., 1991). The range selected for concrete pipe (0.012 to 0.014$)$ was selected. Concrete does comprise most of the collection system conduit construction material; however, because of the age of the collection system this range was later determined to be too low. In addition to concrete pipe, the same range was applied to all other collection system pipe materials. The application of the range of one pipe material to another may not be appropriate. This general application of a range does, however, illustrate just one of the many problems affecting the selection of ranges, and poses the question regarding what extent the parameter uncertainty impacts should be evaluated.

\section{Storage}

The EXTRAN storage parameter was perturbed for each location for which little or no information was available to support the modeling of the physical characteristics. More specifically, storage locations were adjusted if $37 \mathrm{~m}^{3} / \mathrm{m}$ of storage or less occurred at storage junctions and 0.004 ha or less for depth points 1 to 2 at variable storage junctions. As mentioned previously, these storage locations represent a numerical control of model instabilities, whose impact was evaluated. Perturbation was plus and minus $50 \%$ of value (not range). Storage junctions such as basins, pump stations, in-system storage (ISS) review locations, etc. were not evaluated due to the much higher degree of confidence in the physical dimensioning of these locations. Furthermore, these other storage features are much more localized and should be evaluated on a case by case basis, which is beyond the scope of this work.

\section{River Elevation}

The EXTRAN parameter for surface water controlled boundary conditions was assumed to have a range of $1.59 \mathrm{~m}$. This range was based on an average annual historical monthly minimum and maximum Lake St. Clair surface elevation, -0.15 to $1.45 \mathrm{~m}$ from datum $174.5 \mathrm{~m}$ (Department of the Army). This range (not elevations) was assumed to be applicable to all water surface boundary conditions with constant elevations. Simulations were performed for plus and minus 50\% of this range. To simplify the approach, only those outfalls defined as having a constant controlling water surface were varied. Any outfalls that were defined as having free discharge were not modified, even though in some cases these would actually change from free discharge to water surface controlled discharge with an increase in water level. The impact of this is not certain for the high water level simulation. 


\section{Dry Weather Flow}

The EXTRAN and TRANSPORT monthly flow factor parameters were added to the SWMM model by Camp Dresser and McKee to facilitate Phase III GDRSS project needs. These parameters are multiplication factors for the DWF values. For the GDRSS model, these factors are input as monthly values to account for seasonal variation in these flows. Different sets of values are used depending on the location in the system as determined from the source of the data. The ranges for evaluating these monthly factors, and consequently the DWF, were determined for each month based on 1992 wastewater treatment plant (WWTP) flow data. WWTP DWF was analyzed for each month and the upper and lower $95 \%$ confidence interval was used to provide a range for the WWTP factors. The relative difference between the range and the WWTP factors was applied to each set of monthly factors for each region of the system. Simulations were performed for plus and minus $50 \%$ of this range. All monthly factors were set high and low based on ranges specified by percent in Table 12.2 .

In addition to evaluating the impacts of the DWF values on model results, the seasonal variability was evaluated. To address seasonal variability in DWF, the monthly factors were averaged to obtain an annual value for each region.

Table 12.2 DWF range.

\begin{tabular}{cc}
\hline Month & $+/ \%$ \\
\hline Jan & 5.68 \\
Feb & 3.83 \\
Mar & 3.27 \\
Apr & 7.54 \\
May & 3.66 \\
Jun & 4.04 \\
Jul & 4.86 \\
Aug & 6.20 \\
Sep & 8.00 \\
Oct & 2.15 \\
Nov & 2.95 \\
Dec & 4.00 \\
\hline
\end{tabular}

\section{Directly Connected Impervious Area}

The RUNOFF DCIA parameter ranges were based on variation observed in DCIA within each of eleven DCIA parameter evaluation regions. Ranges were defined for residential landuse areas within each region based on the upper and lower $95 \%$ 
Table 12.3 Residential landuse DCIA ranges by region.

\begin{tabular}{lcc}
\hline DCIA Region & \multicolumn{2}{c}{ Range DCIA (\%) } \\
& $95 \%$ LCL & $95 \%$ UCL \\
\hline GDRSSCC & 28 & 47 \\
GDRSSDT & 13 & 46 \\
GDRSSEFWW & 7 & 19 \\
GDRSSFC & 23 & 38 \\
GDRSSSEO & 12 & 43 \\
GDRSSWW & 18 & 21 \\
Lower2 & 11 & 29 \\
Main2 & 18 & 42 \\
Main3 & 13 & 46 \\
Main4 & 17 & 45 \\
Middle3 & 18 & 35 \\
Upper1 & 7 & 19 \\
\hline
\end{tabular}

confidence interval determined from field measured data. These ranges are listed in Table 12.3. Simulations were performed for plus and minus $50 \%$ of ranges. One major assumption was that the variation observed in the residential landuse DCIA would apply to DCIA for all landuse classifications. It is likely that greater uncertainty in DCIA exists for the other landuse classifications; however, further evaluation was beyond the scope of this work.

\section{Depression Storage}

Both the RUNOFF depression storage parameters (impervious and pervious) were based on ranges defined during the GDRSS project small area calibrations. Impervious area depression storage was assigned the range 1 to $3 \mathrm{~mm}$; whereas the pervious area depression storage ranged from 4 to $10 \mathrm{~mm}$. Simulations were performed for plus and minus $50 \%$ of these ranges. These two parameters were aggregated to minimize the number of simulations. By decreasing either depression storage the response to the collection system increases; therefore, both parameters as an aggregate, were either decreased or increased simultaneously.

\section{Evaporation}

The RUNOFF evaporation parameter ranges were based on a hydrology textbook (Viessman et al., 1977). The relative difference was applied by month to the model's baseline annual distribution. This yielded the ranges shown in Table 12.4. Simulations were performed for plus and minus $50 \%$ of range. In addition to 
evaluating the impacts of evaporation on model results, the seasonal variability was evaluated. To address seasonal variability in evaporation, the monthly values were averaged to obtain an annual value. The average is also listed in Table 12.4 as applied to each of 12 months.

Table 12.4 Evaporation.

\begin{tabular}{lcccc}
\hline Month & \multicolumn{4}{c}{ Evaporation $(\mathrm{mm} / \mathrm{day})$} \\
& Baseline & $-50 \%$ range & $+50 \%$ range & Annual Average \\
\hline Jan & 1.3 & 1.1 & 1.4 & 4.1 \\
Feb & 1.8 & 1.5 & 2.0 & 4.1 \\
Mar & 3.0 & 2.6 & 3.5 & 4.1 \\
Apr & 4.3 & 3.7 & 4.9 & 4.1 \\
May & 5.8 & 5.0 & 6.7 & 4.1 \\
Jun & 6.6 & 5.7 & 7.5 & 4.1 \\
Jul & 7.1 & 6.1 & 8.1 & 4.1 \\
Aug & 6.4 & 5.4 & 7.3 & 4.1 \\
Sep & 5.1 & 4.3 & 5.8 & 4.1 \\
Oct & 3.3 & 2.8 & 3.8 & 4.1 \\
Nov & 1.8 & 1.5 & 2.0 & 4.1 \\
Dec & 1.3 & 1.1 & 1.4 & 4.1 \\
\hline
\end{tabular}

\section{Horton's Infiltration and Regeneration}

The RUNOFF parameters for Horton's maximum and minimum infiltration rate, and the decay and regeneration of the infiltration rate were aggregated for simplification. The maximum infiltration ranged from 38 to $76 \mathrm{~mm} / \mathrm{hr}$., minimum infiltration from 0.76 to $8.9 \mathrm{~mm} / \mathrm{hr}$., decay from 0.0007 to $0.0014 \mathrm{~s}^{-1}$, and regeneration from 0.00001 to $0.008 \mathrm{~s}^{-1}$. These ranges were selected by the GDRSS modeling team during their calibration of eight small study area RUNOFF models under three month continuous simulations. The parameters were aggregated such that the direction of influence on model results was the same. For example, to aggregate these terms for the plus $50 \%$ of range simulation, maximum and minimum infiltration rates and regeneration were set to plus $50 \%$ of range $(76 \mathrm{~mm} / \mathrm{hr} ., 8.9 \mathrm{~mm} / \mathrm{hr}$. and 0.008 , respectively) with decay set to minus $50 \%$ of range $\left(0.0007 \mathrm{~s}^{-1}\right)$. Similarly, the aggregation of these terms for the minus $50 \%$ of range simulation consisted of the maximum and minimum infiltration rates, the regeneration and decay being set to $38 \mathrm{~mm} / \mathrm{hr}$., $0.76 \mathrm{~mm} / \mathrm{hr}$., 0.00001 , and $0.0014 \mathrm{~s}^{-1}$, respectively. 


\section{Routing Channels}

The RUNOFF parameters for routing channels used were a combination of a circular pipe and a trapezoidal channel with an orifice (White et al., 1998). Plus and minus $50 \%$ of values were utilized for the simulations instead of parameter ranges due to lack of knowledge regarding reasonable ranges. For consistency, the minus 50\% corresponds to an increase in channel lengths and a decrease in orifice diameter thus producing greater peaked flows to the system and the converse for the plus $50 \%$ of value simulation.

\section{Rainfall Dependent Inflow and Infiltration Shape}

Camp Dresser and McKee recently added code to RUNOFF that includes parameters that define component hydrographs as the basis for the RDI/I response shape. The GDRSS used one direct response hydrograph (predominately inflow) and one delayed response hydrograph (predominately infiltration). The parameters used for these aggregated parameter simulations are the time to peak, ratio of time to recession to time to peak, and the fraction of the response volume assigned to each component hydrograph. These parameters define each hydrograph for a combined set of six parameters. These parameters were evaluated by value, not range, due to lack of information.

Simulations were performed for plus and minus $50 \%$ of value with an exception that plus $20 \%$ of value was applied to the delayed response hydrograph time to peak and ratio due to array limitations of the model code. This array limitation could have been avoided; however, the majority of simulations were performed before this limitation was noticed. The aggregation of parameters for the plus $50 \%$ ( $20 \%$ for delayed component time to peak and ratio) coupled increases in time to peaks and ratios and an increase of the delayed response and decrease of the direct response (overall response volume was kept constant). The plus $50 \%$ ( $20 \%$ for delayed component time to peak and ratio) condition gives greater emphasis on flatter more delayed responses. The converse was applied for the minus $50 \%$ of value giving greater emphasis on a peakier, more direct response.

\section{Rainfall Dependent Inflow and Infiltration Volume}

The RUNOFF parameters for RDI/I response volume are the maximum initial abstraction, initial storage, recovery rate for storage, and the total response volume. Note that the RDI/I shape parameters above also used response volume parameters; however, the shape parameter evaluation used this volume parameter to assign the response volume to either component hydrograph with the total volume kept constant. For the RDI/I volume evaluation, these response volume parameters maintained proportionality between component hydrographs; however, the total volume was adjusted. Table 12.5 lists the ranges used for each of the parameters. 
Table 12.5 RDI/I volume parameter ranges.

\begin{tabular}{lcccccc}
\hline Parameter & \multicolumn{2}{c}{ Dormant } & \multicolumn{2}{c}{ Transition } & \multicolumn{2}{c}{ Growth } \\
& low & high & low & high & low & high \\
\hline DSTORE $(\mathrm{mm})$ & 2.9 & 4.2 & 4.5 & 6.2 & 6.1 & 8.1 \\
STORAGE $(\mathrm{mm})$ & 2.9 & 4.2 & 4.5 & 6.2 & 6.1 & 8.1 \\
DREC (mm/day) & 0.8 & 2.5 & 1.0 & 6.4 & 1.3 & 10 \\
Total RDIIR $(<=30 \mathrm{yrs}, \%)$ & 2.0 & 5.0 & 1.1 & 3.3 & 0.2 & 1.5 \\
Total RDIIR $(>30$ yrs, \%) & 5.0 & 20 & 3.5 & 13 & 2.0 & 6.0 \\
\hline
\end{tabular}

In addition to evaluating the impacts of the RDI/I volume parameter, the seasonal variability was evaluated. To address seasonal variability in RDI/I volume, the monthly parameters for maximum initial abstraction, initial storage, recovery rate for storage, and the total response volume originally defined for growth (June through September), transition (May and November) and dormant (December through April) seasons were averaged to obtain an annual value.

\subsubsection{Seasonally Varying Parameters}

The ranges of the seasonal parameters were evaluated in the same way as the nonseasonal parameters with one exception. The impact of using seasonal variation in model parameters in lieu of average annual values was also evaluated. Evaporation was characterized with monthly values for input into the model throughout the simulation year. Seasonal variation in DWF is due to long-term variation in infiltration and was modeled using monthly flow factors. Flow factors were determined for different flow districts in the model region. These monthly flow factors each had a base factor equal to one during the lowest flow month for the year, October.

Seasonal variation results for the continuous simulations were expected to have little difference on an annual basis. Consequently, the continuous model was also evaluated for a three-month period (March - May, 1984). This period was considered a seasonal extreme for two of the three parameters. Evaporation was not at the extreme during this period, but was slightly above its annual average as shown in Table 12.4. Therefore, a second seasonal extreme period was selected (November 1984 through January 1985) that corresponded to the seasonal extreme for evaporation.

\subsubsection{Accounting of Continuity Error on Results}

Continuity error represents unaccounted for gain or loss in volume through the duration of a simulation. This error is one measure of the model's reliability. For simulations in which the impacts of varying model parameters are small relative 
to the baseline simulation, continuity error may be significant. This is because the simulation results may represent either the parameter variation or the differences in continuity error. This problem is further exacerbated because multiple submodels are used and hydrologic and hydraulic models are coupled i.e., each submodel and each model type had continuity error during the simulations. An approach was developed to account for the impact of the composite continuity error on the results. For each RUNOFF submodel, it is assumed that all the continuity error is due to the calculation of RUNOFF outflow volume i.e., assumes all modeled volumes are calculated without error except the RUNOFF outflow. This gives a worst case evaluation of continuity error impact on the resulting objective statistics, toward treatment and to overflow volumes. This RUNOFF outflow volume is input to the TRANSPORT or EXTRAN models.

By assuming all continuity error is due to the calculation of RUNOFF outflow, a worst case outflow volume is calculated by setting the continuity equation equal to zero. The worst case classification applies provided the assumption that the other flow components of the mass balance are calculated without error. This new RUNOFF outflow volume is then substituted into the TRANSPORT or EXTRAN continuity equation and a composite continuity error is calculated. A similar approach is used for the continuity error in TRANSPORT or EXTRAN outflow points from submodels to the central, downstream-most, submodel. The use of submodel simplifies debugging and simulation and the various models' output are combined using the SWMM COMBINE block. It was not necessary to consider the effects of combined submodels on continuity error for districts within a given submodel, except the coupling of the RUNOFF with either TRANSPORT or EXTRAN. In either case, a composite continuity error value was obtained for each district. This composite continuity error was compared to the TRANSPORT or EXTRAN continuity errors for each district. From this comparison, the largest continuity error was used to calculate a modified relative difference as follows in Equation 12.1:

$$
\text { Difference }=\frac{V_{\text {sim }} \cdot\left(1+\varepsilon_{\text {sim }}\right)-V_{\text {base }} \cdot\left(1+\varepsilon_{\text {base }}\right)}{V_{\text {base }} \cdot\left(1+\varepsilon_{\text {base }}\right)} \cdot 100
$$

Where $V$ is the output volume and $\varepsilon$ is the composite continuity error for the simulation in question and the baseline. The results of Equation 12.1 and 12.2 are compared to ascertain the impacts of continuity error on the results. The continuity error has a significant contribution to the change observed in the model response to the perturbation of a parameter if the relative differences calculated using Equations 12.1 and 12.2 are markedly different. 


$$
\text { Difference }=\frac{V_{\text {sim }}-V_{\text {base }}}{V_{\text {base }}} \cdot 100
$$

For every simulation these two equations are evaluated and compared. Results are discussed in a qualitative context and have not been used to correct model output for continuity error. The continuity error evaluation results are indicators of potential impacts due to numerical error.

Another assumption is that everywhere in a given submodel receives the same continuity error. This assumption is used to apply the continuity error to the district level. Furthermore, the City of Detroit district is unique because it spans two submodels of the TRANSPORT simulations. Consequently, the continuity error is weighted by total outflow from each of the submodels before applying to the relative difference calculation. Likewise for the result totals, the continuity error is weighted for each submodel and applied per Equation 12.1.

\subsubsection{Model Configuration of Precipitation}

The event model (RUNOFF/EXTRAN) and the continuous model (RUNOFF/ TRANSPORT) were each evaluated as coupled hydrologic and hydraulic models. The RUNOFF models were the same for each coupled model with the exception that rainfall records varied between the event and continuous models. The one month $24 \mathrm{hr}$ design event used a simulation period of $144 \mathrm{hrs}$ for all RUNOFF/EXTRAN simulations. The rainfall depth for this design event is 15.7 $\mathrm{mm}$. The rainfall distribution for the one-month event was obtained from previous work performed by the Southeast Michigan Council of Governments (SEMCOG).

A typical three-year (1984 through 1986) precipitation record was used for all RUNOFF/TRANSPORT simulations. The three-year period was chosen because its data has similar statistics to long-term rainfall averages. The spatial and temporal variation in the rainfall record is assumed to be uniform throughout the system i.e., no moving front and the same rainfall distribution over all modeled areas. It should be noted that precipitation is the model input with the greatest impact and its omission from this work should not diminish its importance.

\subsubsection{File Management and Structure}

The same RUNOFF files are used for both EXTRAN and TRANSPORT except that header information and references to precipitation data differ. Any EXTRAN modifications included similar changes to the corresponding hotstart files (files simulated to generate steady state initial conditions) to provide reasonable initial conditions. 


\subsection{Results}

Results are presented first for the continuous model followed by the event model. For each model the seasonal variation impacts and parameter impacts are discussed. The results are presented in terms of overall model totals, the district analysis results are beyond the scope of this chapter. It should be noted that the results for districts that are either predominately separate or combined will differ significantly from this approximately $75 \%$ separate / $25 \%$ combined system.

When parameter uncertainty is undefined then no ranges are established for the parameter, and the parameter impacts analysis is simply a sensitivity analysis. Additionally, the parameters for which ranges have been established can be compared to one another to ascertain relative importance. Relative importance can not be equitably considered for parameters that have no reasonable range defined and is so noted in the results presented.

\subsubsection{RUNOFF/TRANSPORT Results}

\section{Seasonal Variation Impacts}

Table 12.6 summarizes all RUNOFF/TRANSPORT seasonal variation impacts for the three-year continuous simulation and a three-month subset. The threeyear simulations yielded similar results regardless of whether seasonal variation or average annual values are used. Since there tends to be a predominance of larger or higher intensity storms during the three-month seasonal extreme period the annual results do exhibit a slight reduction in flows toward treatment and to overflow when annual averages are in place (with the exception of evaporation discussed below). This observation was expected for annual distribution of rainfall for this three-year period.

The results in Table 12.6 indicate that the DWF seasonal representation is quite significant during the seasonal extreme period. The seasonal variation in the RDI/I representation has significantly less impact. However, although still dominated by DWF, the districts with primarily separate sewers have a significantly greater impact from RDI/I. This result does not imply that seasonal variation in RDI/I can be neglected, because without having performed the parameter analyses regarding the seasonal variation of RDI/I, incorrect annual average values would have been obtained in most cases. For example, if one assumed that RDI/I parameters could be obtained from data collected during the summer months and used as a single annual average value in the model, the model would grossly underpredict the dormant season flows. The seasonal extreme period evaporation values were slightly above the annual average; consequently, the evaporation-only simulation yields even greater difference than when all seasonal variation is converted to annual averages as shown by non-seasonal results. 
Evaporation was evaluated at the seasonal extreme for DWF and RDI/I; however, this period is not the seasonal extreme for evaporation. The seasonal extreme for evaporation is the November to February period as shown in Table 12.4. This time period is a seasonal extreme because lower evaporation can contribute to greater system responses. The evaporation only simulation and the baseline were reanalyzed for a seasonal extreme more relevant to considering the evaporation impacts, November 1984 through January 1985. Table 12.7 shows significant impacts for evaporation during this seasonal extreme.

The influence of continuity error was negligible for all the RUNOFF/ TRANSPORT seasonal variation results. However, the three-month seasonal extreme period results were extracted from the three-year continuous simulation results; therefore, continuity error checks during that period may not be accurate. Even though the observed change is minimal, the period considered for the continuity error may be important. Improved confidence in the continuity error impact estimates would be possible if additional simulations for the three-month period were performed; however, additional simulations were not warranted.

\section{Parameter Impacts}

Table 12.8 summarizes the results for all RUNOFF/TRANSPORT parameter impacts simulations. DWF and evaporation yielded minimal impact on to overflow and some impact on flows toward treatment as expected for continuous simulation.

DCIA, depression storage, and Horton's infiltration all have some impact on flows toward treatment; however, to overflow volumes are greatly impacted by these model parameters. DCIA is a parameter for which a significant amount of field investigation and calibration effort has been performed under this project and related projects. However, these results still show large impacts on model results. If more data were available and the uncertainty in DCIA was reduced (reduction in reasonable range), the impacts on the model would be reduced. Perhaps this parameter should be evaluated at a larger scale i.e., use billing and other existing meters for flow analyses, instead of the small-scale study areas. Then, distribute the large-scale results to the smaller scale for comparison to the more detailed work performed under this study. The model DCIA was obtained from smallscale study results that were extrapolated to the large-scale.

Regardless of approach, DCIA is the dominant parameter of those considered herein with respect to impacting modeled overflow predictions. One should note that both the depression storage and Horton's infiltration simulations are aggregates of two and four parameters, respectively. Since the ranges evaluated for each of the component parameters of these aggregations are set to plus or minus $50 \%$ of each of the parameters' range these impacts may be misleading. For example, it may not be likely that the uncertainty in a set of parameters truly exists at one extreme or the other for all aggregated parameters. 
Table 12.6 Seasonal variation impacts-continuous simulation results.

\begin{tabular}{|c|c|c|c|c|c|c|c|c|c|}
\hline \multirow[t]{2}{*}{ Simulation ID } & \multirow[t]{2}{*}{ Result Type } & \multirow{2}{*}{$\begin{array}{c}\text { Baseline } \\
1,000 \times\left(\mathrm{m}^{3} / \mathrm{yr}\right)\end{array}$} & \multirow{2}{*}{$\begin{array}{l}\text { Annual Avg. } \\
1,000 \times\left(\mathrm{m}^{3} / \mathrm{yr}\right)\end{array}$} & \multicolumn{2}{|c|}{ Relative Difference $(\%)^{*}$} & \multirow{2}{*}{$\begin{array}{c}\text { Baseline } \\
1,000 \times\left(\mathrm{m}^{3} / \mathrm{yr}\right)\end{array}$} & \multirow{2}{*}{$\begin{array}{c}\text { Extreme } \\
1,000 \times\left(\mathrm{m}^{3} / \mathrm{yr}\right)\end{array}$} & \multicolumn{2}{|c|}{ Relative Difference (\%)* } \\
\hline & & & & Unadjusted & Adjusted & & & Unadjusted & Adjusted \\
\hline \multirow[t]{2}{*}{$\begin{array}{l}\text { Non Seasonal (all } \\
\text { as Avg. Annual) }\end{array}$} & $\begin{array}{l}\text { Toward } \\
\text { Treatment }\end{array}$ & 996,019 & 990,213 & -0.6 & -0.5 & 90,773 & 83,273 & -8.3 & -8.2 \\
\hline & To Overflow & 72,890 & 72,508 & -0.5 & -0.5 & 4,895 & 4,619 & -5.6 & -5.6 \\
\hline \multirow[t]{2}{*}{$\begin{array}{l}\text { Dry Weather Flow } \\
\text { as Avg. Annual }\end{array}$} & $\begin{array}{l}\text { Toward } \\
\text { Treatment }\end{array}$ & 996,019 & 995,501 & -0.1 & -0.1 & 90,773 & 83,787 & -7.7 & -7.7 \\
\hline & To Overflow & 72,890 & 72,825 & -0.1 & -0.1 & 4,895 & 4,714 & -3.7 & -3.7 \\
\hline \multirow[t]{2}{*}{$\begin{array}{l}\text { RDII Volume as } \\
\text { Avg. Annual }\end{array}$} & $\begin{array}{l}\text { Toward } \\
\text { Treatment }\end{array}$ & 996,019 & 994,480 & -0.2 & -0.1 & 90,773 & 90,202 & -0.6 & -0.6 \\
\hline & To Overflow & 72,890 & 72,965 & 0.1 & 0.1 & 4,895 & 4,835 & -1.2 & -1.2 \\
\hline \multirow[t]{2}{*}{$\begin{array}{l}\text { Evaporation as } \\
\text { Avg. Annual }\end{array}$} & $\begin{array}{l}\text { Toward } \\
\text { Treatment }\end{array}$ & 996,019 & 992,375 & -0.4 & -0.4 & 90,773 & 90,833 & 0.1 & 0.1 \\
\hline & To Overflow & 72,890 & 72,436 & -0.6 & -0.6 & 4,895 & 4,854 & -0.8 & -0.9 \\
\hline
\end{tabular}

Table 12.7 Evaporation reevaluated.

\begin{tabular}{|c|c|c|c|c|c|c|c|c|c|}
\hline \multirow[t]{2}{*}{ Simulation ID } & \multirow[t]{2}{*}{ Result Type } & \multirow{2}{*}{$\begin{array}{c}\text { Baseline } \\
1,000 \times\left(\mathrm{m}^{3} / \mathrm{yr}\right)\end{array}$} & \multirow{2}{*}{$\begin{array}{l}\text { Annual Avg. } \\
1,000 \times\left(\mathrm{m}^{3} / \mathrm{yr}\right)\end{array}$} & \multicolumn{2}{|c|}{ Relative Difference $(\%)^{*}$} & \multirow{2}{*}{$\begin{array}{c}\text { Baseline } \\
1,000 \times\left(\mathrm{m}^{3} / \mathrm{yr}\right)\end{array}$} & \multirow{2}{*}{$\begin{array}{c}\text { Extreme } \\
1,000 \times\left(\mathrm{m}^{3} / \mathrm{yr}\right)\end{array}$} & \multicolumn{2}{|c|}{ Relative Difference $(\%)$} \\
\hline & & & & Unadjusted & Adjusted & & & Unadjusted & Adjusted \\
\hline $\begin{array}{l}\text { Evaporation as } \\
\text { Avg. Annual }\end{array}$ & $\begin{array}{l}\text { Toward } \\
\text { Treatment }\end{array}$ & 996,019 & 992,375 & -0.4 & -0.4 & 82,506 & 81,372 & -1.4 & -1.4 \\
\hline $\begin{array}{l}\text { (Nov-Jan } \\
\text { Extreme) }\end{array}$ & $\begin{array}{l}\text { To } \\
\text { Overflow } \\
\text { "Adjusted" in }\end{array}$ & $\begin{array}{l}72,890 \\
\text { cludes considera }\end{array}$ & $\begin{array}{l}72,436 \\
\text { n of continuity }\end{array}$ & error per Equati & $\begin{array}{r}-0.6 \\
\ln 12.1\end{array}$ & 2,650 & 2,563 & -3.3 & -3.2 \\
\hline
\end{tabular}


Table 12.8 Parameter impacts-continuous simulation results.

\begin{tabular}{|c|c|c|c|c|c|c|c|c|}
\hline \multirow[t]{3}{*}{ Simulation ID } & \multirow[t]{3}{*}{ Result Type } & \multirow{3}{*}{$\begin{array}{c}\text { Baseline } \\
1,000 \times\left(\mathrm{m}^{3} / \mathrm{yr}\right)\end{array}$} & \multicolumn{2}{|c|}{ Annual Avg. $1,000 \mathrm{x}(\mathrm{m} 3 / \mathrm{yr})$} & \multicolumn{4}{|c|}{ Relative Difference $(\%) *$} \\
\hline & & & \multirow[t]{2}{*}{ Low } & \multirow[t]{2}{*}{ High } & \multicolumn{2}{|c|}{ Low } & \multicolumn{2}{|c|}{ High } \\
\hline & & & & & Unadjusted & Adjusted & Unadjusted & Adjusted \\
\hline \multirow[t]{2}{*}{ Dry Weather Flow } & Toward Treatment & 996,019 & 976,041 & $1,015,939$ & -2.0 & -2.0 & 2.0 & 2.0 \\
\hline & To Overflow & 72,890 & 72,330 & 73,566 & -0.8 & -0.8 & 0.9 & 1.0 \\
\hline \multirow[t]{2}{*}{ DCIA } & Toward Treatment & 996,019 & 971,483 & $1,015,508$ & -2.5 & -2.6 & 2.0 & 2.0 \\
\hline & To Overflow & 72,890 & 48,161 & 106,418 & -34 & -34 & 46 & 46 \\
\hline \multirow{2}{*}{$\begin{array}{l}\text { Depression } \\
\text { Storage }\end{array}$} & Toward Treatment & 996,019 & $1,006,066$ & 988,682 & 1.0 & 1.0 & -0.7 & -0.8 \\
\hline & To Overflow & 72,890 & 86,006 & 64,506 & 18 & 18 & -12 & -12 \\
\hline \multirow[t]{2}{*}{ Evaporation } & Toward Treatment & 996,019 & 997,391 & 994,741 & 0.1 & 0.2 & -0.1 & -0.1 \\
\hline & To Overflow & 72,890 & 73,597 & 72,206 & 1.0 & 1.0 & -0.9 & -0.9 \\
\hline \multirow{2}{*}{$\begin{array}{l}\text { Horton's } \\
\text { Infiltration }\end{array}$} & Toward Treatment & 996,019 & 998,676 & 995,180 & 0.3 & 0.3 & -0.1 & -0.1 \\
\hline & To Overflow & 72,890 & 107,250 & 55,978 & 47 & 47 & -23 & -23 \\
\hline \multirow[t]{2}{*}{ Routing Channels } & Toward Treatment & 996,019 & 999,534 & 992,137 & 0.4 & 0.4 & -0.4 & -0.9 \\
\hline & To Overflow & 72,890 & 69,639 & 73,302 & -4.5 & -4.5 & 0.6 & 0.0 \\
\hline \multirow[t]{2}{*}{ RDII Shape } & Toward Treatment & 996,019 & 994,934 & 997,357 & -0.1 & -0.2 & 0.1 & 0.2 \\
\hline & To Overflow & 72,890 & 74,360 & 71,964 & 2.0 & 1.9 & -1.3 & -1.2 \\
\hline \multirow[t]{2}{*}{ RDII Volume } & Toward Treatment & 996,019 & 994,786 & $1,003,904$ & -0.1 & 0.0 & 0.8 & 0.7 \\
\hline & To Overflow & 72,890 & 72,580 & 75,022 & -0.4 & -0.3 & 2.9 & 2.8 \\
\hline
\end{tabular}


The routing channels, RDI/I shape and RDI/I volume each produced some impact on the to overflow results. The continuity error influence is pronounced for toward treatment and to overflow volumes for routing channels and to a lesser extent for RDI/I shape and RDI/I volume. The accounting of continuity error is discussed in a preceding section. However, depending on the result of interest this may be important.

\subsubsection{RUNOFF/EXTRANResults}

\section{Seasonal Variation Impacts}

The impacts of seasonal variation are presented in Table 12.9 for the RUNOFF/ EXTRAN simulations, and support the results for extreme period analyses. The RUNOFF/EXTRAN A pril event coincides with the three-month extreme period for the continuous simulation (March through May). Evaporation was not considered for the event simulation because the impact was expected to be minimal. Again, the DWF seasonal variation dominated the results. The results indicate model sensitivity to temporal variation of parameters not parameter uncertainty associated with the values. These results indicate that DWF should be evaluated in detail for the periods of model calibration and validation. DWF analysis is fairly easy for event calibration. However, many more analyses are required for continuous simulation to obtain the necessary information regarding seasonal variation.

One should note that continuity error affected the DWF annual average simulation significantly.

Table 12.9 Seasonal variation impacts-event simulation results.

\begin{tabular}{llcccc}
\hline Simulation ID & Result Type & Baseline & Simulation & $\begin{array}{c}\text { Relative Difference } \\
(\%)^{*}\end{array}$ \\
& & $1,000 \times\left(\mathrm{m}^{3}\right)$ & $1,000 \times\left(\mathrm{m}^{3}\right)$ & $\begin{array}{c}\text { Unadjusted } \\
\text { Adjusted }\end{array}$ \\
\hline $\begin{array}{l}\text { Non Seasonal (all as } \\
\text { Avg. Annual) }\end{array}$ & Toward Treatment & 15,539 & 13,768 & -11 & -11 \\
& To Overflow & 958 & 830 & -13 & -13 \\
Dry Weather Flow as & Toward Treatment & 15,539 & 13,933 & -10 & -7.5 \\
Avg. Annual & To Overflow & 958 & 846 & -12 & -8.9 \\
RDII Volume as & Toward Treatment & 15,539 & 15,381 & -1.0 & -1.0 \\
Avg. Annual & To Overflow & 958 & 936 & -2.3 & -2.3 \\
& * "Adjusted" includes consideration of continuity error per Equation 12.1 \\
\end{tabular}




\section{Parameter Impacts}

The parameter impacts results are presented in Table 12.10 for the RUNOFF/ EXTRAN simulations. The three parameters investigated for RUNOFF/EXTRAN only were Manning's $n$, storage and river elevation. Manning's $n$ yielded some impact on the to overflow volume. The impacts of storage were minimal despite varying the parameter by value instead of range. This finding confirms that the use of storage as a stability control measure produces negligible negative impacts. River elevation had a significant impact on to overflow volumes and, when river elevation increased, the flows toward treatment increased significantly.

For the RUNOFF/TRANSPORT simulations, DWF yielded minimal impact on to overflow and some impact on flows toward treatment as expected for continuous simulation. However, the RUNOFF/EXTRAN simulations show that DWF can be an important factor with respect to the to overflow volumes under small storm conditions.

As was observed for the RUNOFF/TRANSPORT simulation results, DCIA and depression storage yielded large model impacts. Depression storage was an aggregated parameter simulation and the depression storage of impervious and pervious area components should be evaluated separately to ascertain which is contributing the most to the results.

Horton's infiltration, an aggregate of four parameters, yielded no impact on the event model results. This is to be expected since the infiltration parameters' impact is dependent on antecedent moisture conditions that are not established for the small single event simulation. The initial conditions of the event simulation begin with the maximum infiltration rate. This maximum rate, even at minus $50 \%$ of range, is sufficient to prevent additional runoff from pervious areas for this small storm. These comments are further supported by the significant impacts observed for the continuous model that accounted for the effects of antecedent moisture and included some greater volume and/or intensity storms.

The routing channels and RDI/I shape each produced significant impact to the model to overflow results. The RDI/I volume parameters produced substantially more to overflow and toward treatment flows. The continuity error influence was negligible for all the RUNOFF/EXTRAN parameter impacts simulation results.

\subsection{Limitations}

The results give some insight into model variability due to uncertainty in parameter values. However, many parameters are not included in the analysis. For example, these analyses did not include the uncertainty in field conditions versus design or as-built drawings for conduit and junction information, pump station representation, basin operation, etc. Furthermore, a number of simplifying 
Table 12.10 Parameter impacts-event simulation results.

\begin{tabular}{|c|c|c|c|c|c|c|c|c|}
\hline \multirow[t]{2}{*}{ Simulation ID } & \multirow[t]{2}{*}{ Result Type } & \multirow{2}{*}{$\begin{array}{c}\text { Baseline } \\
1,000 \times\left(\mathrm{m}^{3}\right)\end{array}$} & \multirow{2}{*}{$\begin{array}{c}\text { Low } \\
1,000 \times\left(\mathrm{m}^{3}\right)\end{array}$} & \multirow{2}{*}{$\begin{array}{c}\text { High } \\
1,000 \times\left(\mathrm{m}^{3}\right)\end{array}$} & \multicolumn{2}{|c|}{ Relative Difference (\%)" } & \multicolumn{2}{|c|}{ Relative Difference (\%) } \\
\hline & & & & & Unadjusted & Adjusted & Unadjusted & Adjusted \\
\hline \multirow[t]{2}{*}{ Mannings " $\mathrm{n}$ " } & Toward Treatment & 15,539 & 15,554 & 15,507 & 0.1 & 0.1 & -0.2 & -0.2 \\
\hline & To Overflow & 958 & 943 & 990 & -1.5 & -1.5 & 3.4 & 3.4 \\
\hline \multirow[t]{2}{*}{ Storage } & Toward Treatment & 15,539 & 15,538 & 15,541 & 0.0 & 0.2 & 0.0 & 0.0 \\
\hline & To Overflow & 958 & 960 & 956 & 0.2 & 0.3 & -0.2 & -0.2 \\
\hline \multirow[t]{2}{*}{ River Elevation } & Toward Treatment & 15,539 & 15,310 & 16,477 & -1.5 & -1.5 & 6.0 & 6.1 \\
\hline & To Overflow & 958 & 1,187 & 816 & 24 & 24 & -15 & -15 \\
\hline \multirow[t]{2}{*}{ Dry Weather Flow } & Toward Treatment & 15,539 & 15,092 & 15,983 & -2.9 & -2.9 & 2.9 & 2.9 \\
\hline & To Overflow & 958 & 928 & 993 & -3.1 & -3.2 & 3.6 & 3.7 \\
\hline \multirow[t]{2}{*}{ DCIA } & Toward Treatment & 15,539 & 14,995 & 15,686 & -3.5 & -3.7 & 0.9 & 0.8 \\
\hline & To Overflow & 958 & 489 & 1,890 & -49 & -49 & 97 & 97 \\
\hline \multirow[t]{2}{*}{ Depression Storage } & Toward Treatment & 15,539 & 15,579 & 15,491 & 0.3 & 0.2 & -0.3 & -0.3 \\
\hline & To Overflow & 958 & 1,056 & 872 & 10 & 10 & -8.9 & -8.9 \\
\hline \multirow[t]{2}{*}{ Horton's Infiltration } & Toward Treatment & 15,539 & 15,539 & 15,539 & 0.0 & 0.0 & 0.0 & 0.0 \\
\hline & To Overflow & 958 & 958 & 958 & 0.0 & 0.0 & 0.0 & 0.0 \\
\hline \multirow[t]{2}{*}{ Routing Channels } & Toward Treatment & 15,539 & 15,608 & 15,506 & 0.4 & 0.4 & -0.2 & -0.1 \\
\hline & To Overflow & 958 & 879 & 1,000 & -8.2 & -8.3 & 4.4 & 4.5 \\
\hline \multirow[t]{2}{*}{ RDII Shape } & Toward Treatment & 15,539 & 15,463 & 15,577 & -0.5 & -0.4 & 0.2 & 0.2 \\
\hline & To Overflow & 958 & 1,051 & 921 & 9.7 & 9.8 & -3.9 & -4.0 \\
\hline \multirow[t]{2}{*}{ RDII Volume } & Toward Treatment & 15,539 & 15,392 & 15,944 & -0.9 & -1.0 & 2.6 & 2.4 \\
\hline & To Overflow & 958 & 967 & 1,062 & 1.0 & 0.9 & 11 & 11 \\
\hline
\end{tabular}

* "Adjusted" includes consideration of continuity error per Equation 12.1 
assumptions were made such as the aggregation of parameters (RDI/I volume, RDI/I shape, depression storage, Horton's infiltration, and routing channels); percent of value was used in lieu of percent of range for some parameters (RDI/ I shape, routing channels and storage); and, seasonally varying parameters were evaluated for changes in value but not distribution. The simplifying assumptions are a limitation in that they make interpreting the results more subjective. Furthermore, only one event was modeled for RUNOFF/EXTRAN. A better approach may have been a multi-event simulation. The range selection and/or the application of the parameter adjustments are to varying extents subjective; consequently, the results may have some biases.

\subsection{Conclusions}

This work attempts to explain to users of the model the impacts of parameter uncertainty. It is not intended to be a detailed uncertainty analysis of the model. Also, seasonal variations were compared to annual average for DWF, RDI/I volume and evaporation. From these results, the critical impacts stem from the DWF for both the continuous and event models. The seasonal extreme for evaporation did not occur during the same period as for DWF and RDI/I. Therefore, another period was considered between the months of November and January to determine seasonal variation impacts due to the evaporation parameter. Evaporation did exhibit a significant impact during the second seasonal extreme period when compared to the annual average.

A summary of parameter impacts is listed in Table 12.11. The critical parameter impacts on the continuous model primarily stem from DCIA. To a lesser extent due to the aggregation of parameters, the depression storage and Horton's infiltration produced significant impacts on the continuous model. Of secondary importance, yet still significant, are the remaining parameters evaluated, with one exception. Evaporation seems to have little impact on the continuous results. Again, it should be emphasized that little impact may stem from a combination of sensitivity of the model to a specific parameter and the uncertainty in the parameter values.

Results obtained from the event simulations are slightly different. The critical parameter impacts on the event model stem primarily from both DCIA and the river elevation boundary conditions. Careful evaluation of river elevation should be made before any design simulations. River elevation was only considered for the event simulation. To a lesser extent, due to the aggregation of parameters, depression storage, routing channels, RDI/I shape and RDI/I volume produced significant impacts on the event model results. For better understanding of the parameters forming the aggregates, one should evaluate the individual parameters. 
Table 12.11 Parameter ranking for continuous and event results.

\begin{tabular}{|c|c|c|c|c|c|c|c|}
\hline \multirow{2}{*}{\multicolumn{2}{|c|}{$\begin{array}{l}\text { RUNOFF/TRANSPORT } \\
\text { Toward Treatment }\end{array}$}} & \multirow{2}{*}{\multicolumn{2}{|c|}{ To Overflow }} & \multicolumn{4}{|c|}{ RUNOFF/EXTRAN } \\
\hline & & & & \multicolumn{2}{|c|}{ Toward Treatment } & \multicolumn{2}{|c|}{ To Overflow } \\
\hline Rank & Parameter & Rank & Parameter & Rank & Parameter & Rank & Parameter \\
\hline 1 & DCIA & 1 & DCIA & 1 & River Elevation & 1 & DCIA \\
\hline 2 & Dry Weather Flow & 2 & Horton's Infiltration & 2 & Dry Weather Flow & 2 & River Elevation \\
\hline 3 & Depression Storage & 3 & Depression Storage & 3 & DCIA & 3 & Depression Storage \\
\hline 4 & RDII Volume & 4 & Routing Channels & 4 & RDII Volume & 4 & RDII Shape \\
\hline 5 & Routing Channels & 5 & RDII Volume & 5 & RDII Shape & 5 & Routing Channels \\
\hline 6 & Horton's Infilltration & 6 & RDII Shape & 6 & Routing Channels & 6 & RDII Volume \\
\hline 7 & Evaporation & 7 & Evaporation & 7 & Depression Storage & 7 & Dry Weather Flow \\
\hline \multirow[t]{3}{*}{8} & RDII Shape & 8 & Dry Weather Flow & 8 & Mannings "n" & 8 & Mannings "n" \\
\hline & & & & 9 & Storage & 9 & Storage \\
\hline & & & & 10 & Horton's Infiltration & 10 & Horton's Infiltration \\
\hline Notes: & \multicolumn{7}{|c|}{$\begin{array}{l}\text { Parameters with beld text indicates that continuity error could effect the order of impact ranking. } \\
\text { Parameters with italic text indicates that percent of value was used instead of percent of range (equitable ranking is } \\
\text { void, presented for reference only) }\end{array}$} \\
\hline
\end{tabular}


Of secondary importance, yet still significant, are the remaining parameters considered for the event simulations, except storage and Horton's infiltration aggregate, which both produced little impact. Even though representing model sensitivity only, the results are quite important because of the use of storage as a numerical instability control rather than as a representative physical component of the system. The addition of storage volumes used in the GDRSS model to control model instabilities has negligible impacts on model results.

\section{Acknowledgments}

The Greater Detroit Regional Sewerage System model development is being conducted by the Detroit Water and Sewerage Department (DWSD). The authors of this chapter would like to acknowledge Gary Fujita, P.E., Assistant Director of Wastewater Operations of DWSD for his guidance and assistance during the several years of the development and use of this model. We are grateful to Philip N. Brink, P.E., of Camp Dresser \& McKee and David A. White, P.E., of Wade-Trim Associates for assisting with post-processing.

\section{References}

Department of the Army Detroit District Corp of Engineers, 1997. Monthly Bulletin of Lake Levels for the Great Lakes, April 1997.

James, W. and A. Kuch. 1998. "Sensitivity-calibration Decision-support Tools for Continuous SWMM Modeling: a Fuzzy-logic Approach." Journal of Water Management Modeling R200-09. doi: 10.14796/JWMM.R200-09.

Potter, M. C. and D. C. Wiggert, 1991. Mechanics of Fluids, Prentice-Hall, Inc.

Sherman, B.J., P. Brink and M.J. TenBroek. 1998. "Spatial and Seasonal Characterization of Infiltration/Inflow for a Regional Sewer System Model."

Journal of Water Management Modeling R200-13. doi: 10.14796/JWMM.R200-13.

Sherman, B. J, and M. J. TenBroek. 1997. Hydrologic and Hydraulic Computer Model Computer Model Parameter Distribution, Projection, and Correlation Development Using Geographic Information System. In Proceedings, Seventeenth Annual ESRI user Conference. Environmental Systems Research Institute, Inc., San Diego, California, July 8-11, 1997.

TenBroek, M.J., G. Fujita, P. Brink, B.J. Sherman and D. White. 1999. "Detroit Water and Sewerage Department Model Extensions and Project Overview." Journal of Water Management Modeling R204-11. doi: 10.14796/JWMM.R204-11.

Viessman Jr., W., J. W. Knapp, G. L. Lewis, and T. E. Harbaugh, 1977. Introduction to Hydrology, Harper \& Row, Publishers. 
White, D., B. Boddy and J.D. Sherrill. 1998. "Improved Combined Sewer Area Inflow Hydrograph Representation." Journal of Water Management Modeling R200-14. doi: 10.14796/JWMM.R200-14. 